\title{
Syringosubarachnoid shunt for syringomyelia associated with Chiari I malformation
}

\author{
Amit Agarwal · Krishnamoorthy Thamburaj
}

Received: 23 March 2010 /Revised: 24 June 2010 /Accepted: 30 June 2010 /Published online: 20 August 2010

(C) Springer-Verlag 2010

An 11-year-old girl with Chiari I malformation presented with a large cervico-thoracic syrinx (Fig. 1). There was poor clinical improvement 4 months after foramen magnum decompression. Subsequently, syringosubarachnoid shunting was performed, resulting in complete resolution of the syrinx and marked clinical improvement. The shunt was seen as a small tubular structure on MRI, with prominent flow artifact within the thecal sac near the shunt opening (Fig. 2).

Syringomyelia associated with Chiari I malformation can be treated by foramen magnum decompression, syringosubarachnoid shunting and syringoperitoneal shunting $[1,2]$. Syringosubarachnoid shunting is a safe, effective and techni-

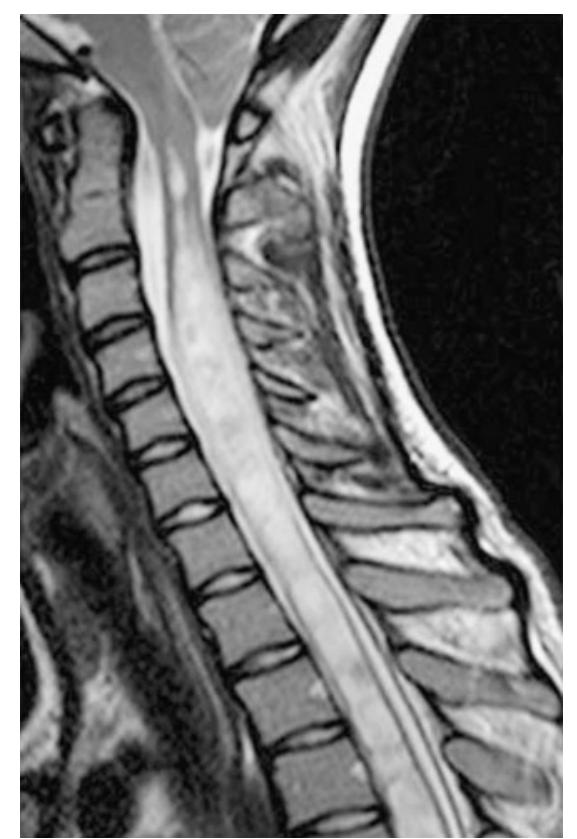

Fig. 1 Sagittal T2-W MRI, pre-shunting

\footnotetext{
A. Agarwal $(\bowtie) \cdot K$. Thamburaj

Department of Radiology,

Penn State University Hershey Medical Center,

500 University Drive,

Hershey, PA 17036, USA

e-mail: amitmamc@gmail.com
}

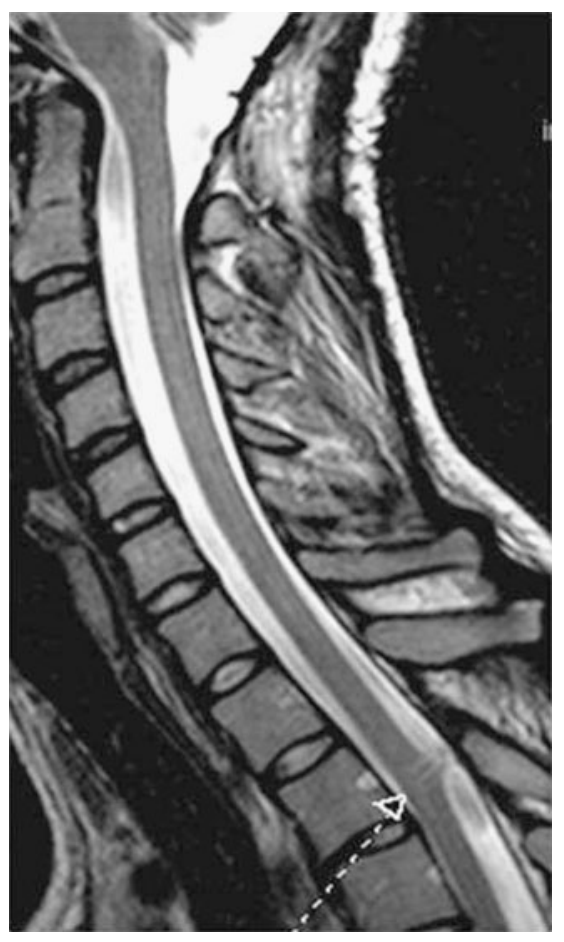

Fig. 2 Sagittal T2-W MRI, post-shunting

cally simple technique that is preferred for use with large syringes or for rapid progression of clinical symptoms [2]. The shunt catheter is identified on MRI as a tubular structure, usually along the posterolateral part of the cord, with flow artifact near the subarachnoid opening.

\section{References}

1. Batzdorf U (1988) Chiari I malformation with syringomyelia: evaluation of surgical therapy by magnetic resonance imaging. $\mathrm{J}$ Neurosurg 68:726-730

2. Hida K, Iwasaki Y, Koyanagi I et al (1995) Surgical indication and results of foramen magnum decompression versus syringosubarachnoid shunting for syringomyelia associated with Chiari I malformation. Neurosurgery 37:673-678 